\section{Commentary: Snakes under every rock}

\author{
Yogesh Patel, MD, and Chadrick E. Denlinger, MD
}

Testicular cancers are rare, but they are also the most prevalent tumors in young men and their incidence continues to rise, with a projected $20.4 \%$ increase in new cases and $39.8 \%$ increase in mortality by $2040 .{ }^{1}$ Testicular cancers, even with germ cell metastases, if treated aggressively are often eradicated with 5-year survival rates reaching $90 \%$. Despite effective chemotherapy, $15 \%$ to $20 \%$ of patients with disseminated disease experience recurrence and most relapses occur within the first 5 years. ${ }^{2}$ Currently, there are no randomized trials informing decisions related to metastaectomy for germ cell tumors, leading to interinstitutional management variability. General consensus supports germ cell metastatectomy, especially with pulmonary nodules because it can provide high cure rates. However, many resected nodules are later determined to be benign, causing some to question the necessity of every operation.

Donahoe and colleagues ${ }^{3}$ performed a single-institution retrospective review of 89 patients over the course of 13 years to determine whether concordance rates between metastatic sites could be used to guide surgical treatment algorithms. ${ }^{3}$ Ninety percent of patients (9 out of 10$)$ with benign histology found during their initial pulmonary nodule resection also had benign disease identified on subsequent pulmonary resections. However, 1 subsequently had a malignant nodule. Similarly, 3 out of 11 patients with pulmonary and mediastinal lesions had malignant histology on subsequent resections after an initial resection of benign disease. Although the histological concordance rates for germ cell metastatic sites was $81 \%$, the authors' conclusion that $19 \%$ discordance rate mandates resection of subsequent lesions rather than trust that resection of a previous

\footnotetext{
From the Division of Cardiothoracic Surgery, Indiana University, Indianapolis, Ind. Disclosures: The authors reported no conflicts of interest.

The Journal policy requires editors and reviewers to disclose conflicts of interest and to decline handling or reviewing manuscripts for which they may have a conflict of interest. The editors and reviewers of this article have no conflicts of interest.

Received for publication Nov 18, 2020; revisions received Nov 18, 2020; accepted for publication Nov 19, 2020; available ahead of print Nov 28, 2020.

Address for reprints: Chadrick E. Denlinger, MD, Division of Cardiothoracic Surgery, Indiana University, 545 Barnhill Dr, EH 215, Indianapolis, IN 46202 (E-mail: cdenlinger@iuhealth.org).

J Thorac Cardiovasc Surg 2021;161:869-70

0022-5223/\$36.00

Copyright (C) 2020 by The American Association for Thoracic Surgery

https://doi.org/10.1016/j.jtcvs.2020.11.092
}

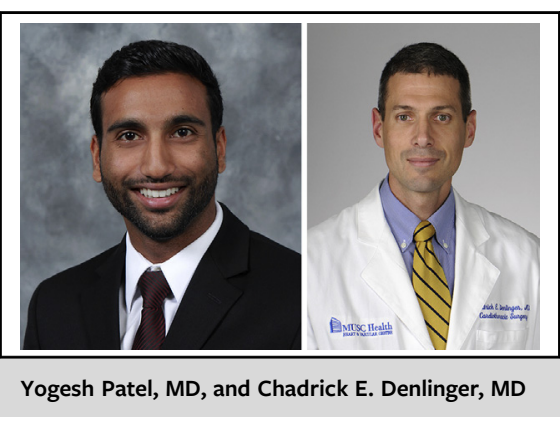

CENTRAL MESSAGE

The histology of malignant germ

cell metastases is not reliably

predicted by an individual's his-

tory or serum tumor markers.

Aggressive resection is appro-

priate for the majority of these

nodules.

benign nodule reliably predicts that subsequent nodules are also benign.

Serum tumor markers (STMs) also had inadequate sensitivity and specificity to warrant making absolute decisions against surgical resection of pulmonary nodules. STM remains an important element in the management of mediastinal germ cell tumors and they help guide whether residual masses should be treated by resection, chemotherapy, or surveillance. In this series, STMs before resection correlated with malignant histology. However, 9 patients with normal STMs actually had viable malignancies. Furthermore, normal STMs at the time of resection related to lower survival rates owing to somatic transformation. This corroborates previous findings by Schekel and colleagues ${ }^{4}$ that showed that germ cell tumors with malignant somatic transformation portends a worse prognosis, with survival rates of $50 \%$ to $60 \%$. STMs are vital; however, they should not be the sole information upon which clinicians rely to guide management of metastatic nonseminomatous germ cell cancer. Donahoe and colleagues ${ }^{3}$ demonstrated histological correlations between serial resections of mediastinal and pulmonary lesions in the settings of germ cell tumors and relations of STMs and malignancies that are insufficient to direct surgical interventions for new lesions. As a result, these data imply that new thoracic lesions should be managed aggressively with surgical resection that contributes to long-term cancer survival. This approach is analogous to assuming that there may be a snake hiding under every rock. 


\section{References}

1. Bray F, Ferlay J, Soerjomataram I, Siegel RL, Torre LA, Jemal A. Global cancer statistics 2018: GLOBOCAN estimates of incidence and mortality worldwide for 36 cancers in 185 countries. CA Cancer J Clin. 2018;68:394-424.

2. Lobo J, Gillis AJM, Jerónimo C, Henrique R, Looijenga LHJ. Human germ cell tumors are developmental cancers: impact of epigenetics on pathobiology and clinic. Int J Mol Sci. 2019;20:258.
3. Donahoe LL, Nason GJ, Bedard PL, Hanse AR, Jewett MAS, Hamilton RJ, et al. Pathologic concordance of resected metastatic nonseminomatous germ cell tumors in the chest. J Thorac Cardiovasc Surg. 2021;161:856-68.e1.

4. Scheckel CJ, Kosiorek HE, Butterfield R, Ho TH, Hilal T. Germ cell tumors with malignant somatic transformation: a Mayo Clinic experience. Oncol Res Treat. 2019;42:95-100.
See Article page 856 .

\section{Commentary: Good news travels fast}

\section{Kenneth A. Kesler, MD}

Before the results of a phase II trial demonstrating the effectiveness of cisplatin-based chemotherapy for disseminated testicular cancer were published in 1976, the word was out and survival rates began to exponentially increase for a malignancy, which at the time was rarely cured. ${ }^{1,2}$ The treatment algorithm of combination chemotherapy followed by aggressive surgery to remove residual disease for metastatic nonseminomatous germ cell tumors is now considered one of most successful models for multimodality cancer therapy, which our thoracic oncology community emulates for other locally advanced neoplasms with improved but currently lesser success.

Although cure rates for testicular cancer are very high, there still remain frontiers for improvement, such as the quandary of chemorefractory nonseminomatous cancer and malignant (somatic) transformation (fortunately representing only a minority of cases) and the variety of postchemotherapy pathology, which has implications for the indications to remove residual disease. For 2 examples, avoidance of pulmonary metastasectomy would seem prudent where there is a high likelihood of complete tumor necrosis. In contrast, pulmonary metastasectomy for numerous areas of chemorefractory disease may be futile.

From Division of Thoracic Surgery, Department of Surgery, Indiana University Melvin and Bren Simon Cancer Center, Indianapolis, Ind.

Disclosures: The author reported no conflicts of interest.

The Journal policy requires editors and reviewers to disclose conflicts of interest and to decline handling or reviewing manuscripts for which they may have a conflict of interest. The editors and reviewers of this article have no conflicts of interest.

Received for publication Nov 15, 2020; revisions received Nov 15, 2020; accepted for publication Nov 17, 2020; available ahead of print Nov 25, 2020.

Address for reprints: Kenneth A. Kesler, MD, Thoracic Surgery Division, Department of Surgery, Indiana University, Barnhill Dr, EM \#212, Indianapolis, IN 46202 (E-mail: kkesler@iupui.edu).

J Thorac Cardiovasc Surg 2021;161:870-1

$0022-5223 / \$ 36.00$

Copyright (c) 2020 by The American Association for Thoracic Surgery

https://doi.org/10.1016/j.jtcvs.2020.11.063

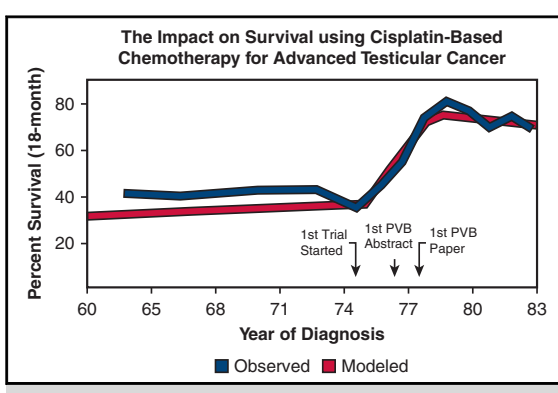

Survival of disseminated testes cancer by year of diagnosis (from Feuer and colleagues ${ }^{\top}$ ).

\section{CENTRAL MESSAGE \\ Metastatic germ cell tumors have high cure rates with cisplatin chemotherapy followed by sur- gery. Although teratoma is the most common pathology, other benign and malignant elements can be present.}

Donahoe and coworkers ${ }^{3}$ have taken a deep dive into their institutional experience, examining the pathology and survival outcomes after surgery for nonseminomatous testicular cancer metastatic to the lung and mediastinum. The authors' messages are important. First, the ability to predict postchemotherapy pathology is overall good, taking under consideration serum tumor marker levels, computed tomography appearance, and orchiectomy pathology, but the predictive accuracy as well as the concordance between lung, mediastinum, and retroperitoneal pathology remains imperfect. Second, while "benign" teratoma is the most common pathology in residual abnormalities following chemotherapy, there can be a variety of other benign and malignant elements. In this regard, this manuscript also serves to educate on the spectrum of pathology that can be encountered. Finally, careful, long-term surveillance after surgery, with removal of recurrent disease when appropriate, is necessary to maintain optimal outcomes. 